\title{
Estado, política e evolução social: uma tendência para este século XXI
}

Leno Francisco Danner*

Resumo: Defenderei o argumento de que, desde a última década do século XX, se está assistindo a uma reafirmação de um Estado forte, compensatório e regulatório, diretivo em relação à evolução social. Nesse sentido, passa para o primeiro plano a política - tanto em termos de afirmação das instituições políticas quanto no que se refere à participação cidadã - como o elemento fundamental para a realização de transformações em todos os âmbitos da sociedade. Contratendências conservadoras na política, redivivas diante da atual crise socioeconômica, defensoras de políticas de austeridade como forma de resolver-se tal crise, e depois de um longo tempo de influência das posições neoliberais, podemos perceber a consolidação de uma cultura democrática ou de uma mentalidade coletiva afirmadora desse Estado diretivo em relação à evolução social, realizador de políticas de integração social e regulador no que tange à dinâmica econômica. É uma realidade muito importante para nossas democracias, pois leva ao reforço de uma cultura pública defensora de direitos sociais, à afirmação de uma política que, contraposta ao laissez-faire, assume o papel de centro diretivo da sociedade, de espaço de reivindicações por justiça e de exercício efetivo da cidadania, por parte de um número sempre crescente de indivíduos, grupos culturais e movimentos sociais os mais diversos. Trata-se, por isso, de uma perspectiva muito otimista no que diz respeito ao reforço da democracia política, que coloca o Estado como instituição básica para a constituição de uma sociedade democrática contemporânea.

Palavras-chave: política, Estado, sociedade, economia, contemporaneidade.

\section{O ocaso do conservadorismo político}

Q uero partir do argumento de que estamos assistindo, desde meados da década de 1990, a um enfraquecimento vertiginoso do conservadorismo político-econômico representado pelo modelo neoliberal, situação socioolítica que contrasta com o período que, iniciado em meados da década de 1970 e chegando até praticamente o fim dos anos 1990, teria sido marcado, em decorrência da hegemonia neoliberal, pelo ataque ao Estado de bem-estar e pela abertura praticamente inconteste das sociedades ocidentais à globalização econômica, dando a tônica dos discursos e das reformas neoliberais implementadas neste período (Katz, 1989; Duggan, 2003; Habermas, 2003; Zurn \& Leibfried, 2007). Em certo sentido, portanto, o tempo do neoliberalismo esgotou-se ou, pelo menos, este mesmo neoliberalismo perdeu sua capacidade (supondo que a teve em algum momento) de responder aos desafios de governabilidade e integração - de conciliação entre capital e trabalho, entre democracia e capitalismo - nas sociedades contemporâneas e em termos de globalização econômico-cultural, o que significa que
Recebido: 11.03 .15

Aprovado: 24.08 .16
* Doutor em filosofia (PUC-RS), professor do Departamento de Filosofia da Universidade Federal de Rondônia (Unir). É especialista em teoria política, particularmente em Marx e no marxismo, liberalismo político e teoria crítica. <leno_ danner@yahoo.com. br>. 
mais uma vez um modelo de política e de Estado fortes são chamados ao enfrentamento dos problemas sociais originados pela dinâmica econômica de acumulação e de exploração do trabalho, agora dinamizada desde um horizonte econômico-político globalizado que se, por um lado, é marcado pela presença de vários blocos de poder e de centros econômicos, não necessariamente alinhados, por outro, obedece a uma mesma lógica político-econômica, a saber, o crescimento econômico às custas da exploração do trabalho aos moldes do sistema produtivo asiático (baixos salários, parca organização sindical, altíssima exploração do trabalho) - modelo esse fomentado em termos de transnacionalização do capital desde o âmbito anglo-americano ou euronorcêntrico e consolidado neste início de século XXI como a forma hegemônica de relação entre capital e trabalho em termos de globalização econômica (Arrighi, 2008; Boltanski \& Chiapello, 2009; Bauman, 2010; Napoleoni, 2014).

Note-se, no que diz respeito aos múltiplos blocos de poder - modelos políticos e econômicos em termos de Realpolitik -, no cenário regional-global hodierno, que há um mesmo padrão político-organizacional que perpassa a autoconstituição e o funcionamento das grandes economias atuais - pensemos nos Estados Unidos, na Europa Ocidental, na China, no Japão e nos Tigres Asiáticos, para não se falar também no Mercosul, a saber, a afirmação da lógica da globalização econômica vigente enquanto naturalização do capitalismo transnacional que conjuga abertura direta ao mercado internacional e a liberalização dos fluxos de capitais transnacionais, o enfraquecimento da força política dos movimentos sociais por meio do acirramento da tecnocracia e, de um modo mais geral, a consolidação gradativa de uma forma de produção material que intensifica os baixos salários, a degradação dos direitos trabalhistas e o aumento da carga laboral, ao estilo dos mercados de trabalho da Ásia -, mercados esses que, como argumentarei ao longo do texto, servem de modelo político-econômico, hoje, para a recomposição do capitalismo global contra a consolidação dos movimentos democrático-trabalhistas contrapostos às políticas de austeridade enquanto receituário neoconservador para a resolução da atual crise socioeconômica, até mesmo como reação ao crescimento dos governos vinculados à esquerda teórico-política, nestas duas primeiras décadas do século XXI. Nesse sentido, não é possível nos enganarmos quanto a diferenças mais específicas em termos de política internacional relacionada à globalização levada a efeito pelos Estados Unidos, pela União Europeia ou, na Ásia, pela China, pelo Japão e pelos Tigres Asiáticos: há, como defendo, um cerne comum a todos estes blocos político-econômicos de poder, que consiste na aceitação e na consolidação de um mercado mundial caracterizado cada vez mais pela precarização do trabalho como um de seus cernes centrais e enquanto o modelo hegemônico de produção econômica material própria do capitalismo para este século XXI - um ponto central, diga-se de passagem, na atual agenda neoconservadora, tanto no Brasil como mais além, ao 
dar prioridade absoluta à abertura econômica, ao aumento das taxas de juros (que favorece ao regime rentista dos capitais especulativos e leva à desindustrialização e à desnacionalização da economia) e às políticas de austeridade realizadas pelo Estado. É nesse contexto, por conseguinte, que um modelo de política e de Estado fortes tornam-se fundamentais para enfrentar-se o crescimento das posições neoconservadoras e a retomada da austeridade política (altas taxas de juros, abertura econômica à globalização dos capitais transnacionais, redução dos investimentos públicos em inclusão social, precarização do trabalho). É nesse contexto, ainda, que a nova cidadania democrática surgida nas últimas décadas, caracterizada pela participação política direta e cada vez mais incisiva, coordenada local, nacional e internacionalmente, pode fazer frente e mitigar a força das posições teórico-políticas neoconservadoras, instaurando um modelo político alternativo de instituições públicas, de Estado e de desenvolvimento social, assim como de participação política democrática.

Efetivamente, retomando meu argumento acerca da atualidade de um modelo de política e de Estado fortes, bem como de crise e de ocaso do neoliberalismo, desde fins dos anos 1990 é possível percebermos, na análise da Realpolitik de inúmeras democracias ocidentais - da Europa ocidental, passando pelos Estados Unidos e chegando às nossas Américas - um reforço da política social e a afirmação de um Estado forte, interventor na esfera econômica e compensatório na esfera social, que centraliza a condução da evolução social, colocando a política democrática, contrariamente ao que defendia o neoliberalismo, como o baluarte da evolução destas mesmas democracias (Esping-Andersen, 1999, 2003; Danner, 2013, 2014a). Ora, dois dos pilares básicos da posição neoliberal - a recusa da sociedade e de suas instituições enquanto estruturas objetivas que determinam poderosamente tanto a evolução social quanto a atribuição do status quo e a afirmação da autorreferencialidade da esfera econômica, que, devido a uma dinâmica própria, não política e não normativa, não poderia nem sofrer intervenção política, nem ser enquadrada a partir de argumentos normativos e de interesses generalizáveis próprios do âmbito social - foram implodidos pela mudança sociopolítica que desde aquele período tem dinamizado a autoconstituição de nossas democracias e a visão política hegemônica em nossas sociedades, formando uma nova cultura democrática que tem seu cerne na defesa de um modelo de política e de Estado fortes, de instituições públicas atuantes socialmente e de direitos sociais de cidadania universalizados, cultura democrática essa que é ferreamente contraposta ao neoliberalismo e desconfiada da abertura ingênua da economia nacional à globalização econômica.

Primeiramente uma digressão sobre estes dois pilares da posição neoliberal. Hayek (2008), considerado o pai do neoliberalismo, partia da ideia de que a evolução 
social possui caráter espontâneo, sendo dinamizada por indivíduos sem qualquer visão messiânica ou filosófica do todo, preocupados basicamente com a satisfação de suas necessidades pessoais, que é obtida em um processo correlato de oferta dos próprios talentos aos demais e de aproveitamento dos talentos oferecidos por estes. Para Hayek, são estas ações isoladas, levadas a efeito por indivíduos que, como disse, querem apenas satisfazer seu bem-estar pessoal, que fazem com que esses mesmos indivíduos instituam, ao longo do tempo, práticas, códigos e regras que possam orientar as relações entre eles e arbitrar sobre reivindicações de justiça surgidas a partir daquelas relações. Note-se bem que a tônica da evolução social-institucional é determinada por indivíduos singulares, e não pelas instituições ou por noções abstratas e genéricas de classe social - instituições e classes sociais que poderiam representar estruturas e macrossujeitos da evolução social, determinadores da dinâmica realizada em uma dada sociedade e mais além (um argumento básico da teoria social de um modo geral e da teoria social de esquerda em particular).

Para Hayek, portanto, a evolução social, isto é, a consolidação de resultados objetivos no que tange ao status quo e à formação das instituições em uma dada sociedade, e mesmo a evolução da própria sociedade de um modo mais genérico, acontecem de modo espontâneo e não intencional, a partir daquelas múltiplas ações individuais, feitas com o intuito de satisfazer os próprios interesses singulares. Ou seja, essa evolução é espontânea e não intencional porque não foi produzida conscientemente, porque não foi conduzida por alguma instituição ou classe social, porque não foi centralizada pelas instituições e classes sociais. Ela não foi pensada ou planejada, simplesmente aconteceu por meio desse processo de inter-relação produtiva entre indivíduos singulares que, conforme travavam relações de troca, percebiam o que deveria ser seguido e o que deveria ser condenado em termos dessas mesmas inter-relações produtivas. Três ideias importantes aparecem aqui: a importância da esfera econômico-produtiva em termos de evolução social; a recusa de que a sociedade e suas instituições, correlatamente à ideia de classes sociais (no sentido a elas dado por Marx), sejam estruturas objetivas ou macrossujeitos da evolução social; e a recusa da política e do Estado enquanto médium basilar da evolução social e instituição planejadora dessa mesma evolução social, concomitantemente à afirmação, por parte de Hayek, de que o mercado é uma ordem espontânea que, por sua lógica própria, não normativa e não política, assume o papel de lugar por excelência da evolução social (Hayek, 1985a, 1985b; Butler, 1987).

Explico brevemente cada uma dessas ideias. A primeira delas diz respeito ao fato de que esse processo evolutivo tem seu cerne na esfera econômica, na produção da vida material: é por meio da busca pela satisfação das próprias necessidades no âmbito produtivo que os indivíduos singulares contribuem para a gestação de prá- 
ticas, normas e instituições sociais. Isso demonstra a importância que a esfera econômica possui para a definição da dinâmica social, para a configuração - ainda que de forma indireta, espontânea - da sociedade: indivíduos singulares produzem sua vida material e, a partir disso, geram códigos e práticas objetivos, que chamamos de sociedade, de instituições, de cultura etc. A segunda delas diz respeito à recusa de que a sociedade e suas instituições sejam estruturas objetivas que, a partir das lutas entre supostas classes sociais e da configuração dali adquirida, definam o status quo, o ritmo, a intensidade e a configuração da evolução social, dos processos de socialização e de subjetivação. Afirmar a ideia de que a sociedade e suas instituições são estruturas objetivas equivale a acreditar que a sociedade tenha um centro (ou alguns centros diretivos, planejadores, estruturantes) e macrossujeitos por sobre as cabeças individuais; equivale também a pressupor a possibilidade de, politicamente, se poder planejar os processos evolutivos, que não seriam, nesta posição, concebidos como espontâneos, e sim como produzidos politicamente, planejados a partir das instituições, tecnocraticamente. Da mesma forma, a afirmação de macrossujeitos da evolução social implica em que sejam anuladas as ações individuais que, como quer Hayek, são a verdadeira causa - inconsciente, não intencional e não planejada - de uma evolução social com caráter abrangente, definidora das características gerais da sociedade, de seus códigos e de suas relações. Instituições e macrossujeitos não existem, a não ser como idealizações. Na prática, apenas existem indivíduos e as relações que estes entabulam entre si com vistas ao proveito próprio (Hayek, 1987; Butler, 1987).

Com isso, chegamos à terceira ideia central para a posição neoliberal, a saber, a recusa da política democrática e do Estado enquanto elementos diretivos da evolução social, instâncias a partir das quais essa mesma evolução social pode ser racionalizada, discutida, planejada conscientemente e levada a efeito praticamente. Hayek nega esse papel diretivo e planejador da evolução social que tradicionalmente - em particular nas posições de esquerda - a política democrática e o Estado têm assumido e mesmo centralizado. As teorias de índole socialista (e, hodiernamente, sua vertente social-democrata) apresentam exatamente essa característica de atribuir centralidade à política democrática e ao Estado devido ao fato de conceberem a sociedade e suas instituições como estruturas objetivas, macroestruturas que, devido a esse seu caráter, influem direta e decisivamente nos processos de evolução social e na determinação do status quo. Além disso, tais instituições não seriam imunes aos grupos de poder ou classes sociais que, ao estilo de macrossujeitos, definiriam, a partir de suas lutas por poder e hegemonia, configurações institucionais, práticas culturais e dinâmicas sociopolíticas. Assim, nas teorias políticas de esquerda, a ação política de classe e o planejamento institucional da evolução social passam para primeiro plano, permitindo tanto a configuração adequada dos sistemas sociais, 
econômicos, políticos e culturais, quanto a racionalização da dinâmica social que, planejada e conduzida desde as instituições, poderia adquirir um sentido mais equitativo e inclusivo e menos arbitrário (porque consciente e fundado em interesses generalizáveis e argumentos normativos).

Ora, Hayek ataca esse aguilhão da teoria social de esquerda no momento em que não apenas concebe a evolução social como espontânea, não intencional e não planejada, senão também na medida em que, para fazer isso, estabelece a centralidade do horizonte econômico-produtivo como motor dessa mesma evolução social. O mercado, enquanto ordem espontânea, é uma esfera não objetiva, não estrutural, na qual o fator básico da diferenciação entre os indivíduos e, consequentemente, da evolução social é a meritocracia, garantida a partir da livre concorrência. Aqui, não é o planejamento institucional centralizado ou a condução política das atividades econômicas dos indivíduos que garantirão uma evolução social equitativa, mas a própria espontaneidade do âmbito econômico-produtivo, isto é, a ampla mobilidade dos indivíduos em estabelecerem relações de troca uns com os outros, que é responsável seja pela produção da vida material, seja pela consolidação do status quo, seja, por fim e como consequência, pela formação de regras, práticas e códigos intersubjetivos. Assim, as instituições de um modo geral e o Estado em particular são importantes, na teoria de Hayek, mas o são por apenas dois motivos básicos: garantir o respeito e o cumprimento dos contratos e dos pactos, bem como evitar que o âmbito econômico seja afetado por poderes estruturais e por reivindicações normativas realizadas por meio de intervenções políticas. Quanto menos controles e intervenções políticas, mais espontaneidade. Quanto mais espontaneidade e liberdade, mais justiça e igualdade, que passam a ser definidas pela meritocracia do trabalho e pela livre concorrência - posto que a normatividade é uma ilusão dos grupos sociais perdedores em termos de meritocracia. A meritocracia do trabalho, aliás, torna-se o único critério para a definição do status quo, o que significa que, conforme já comentado acima, reivindicações normativas por igualdade material, distribuição da riqueza e justiça social não passem de uma "miragem" (termo utilizado por Hayek) usada por grupos sociais perdedores, não podendo legitimar uma política diretiva e um Estado forte que enquadrem o sistema econômico com base em interesses generalizáveis. Desse modo, torna-se claro que o alvo da crítica de Hayek, fundamental para sua posição política, consiste na centralidade da política democrática e do Estado de bem-estar social enquanto elementos diretivos, condutores e planejadores da evolução social, que, a partir de argumentos normativos e interesses generalizáveis, e por meio de participação política permanente, incisiva e direta, enquadram o âmbito econômico com o objetivo de se realizar valores de uso. A boa política, conforme defendido pelo neoliberalismo, é aquela que garante o máximo de espontaneidade à esfera econômico-produtiva, deixando a meritocra- 
cia definir tanto o status quo como os rumos da evolução social. A má política, por sua vez, é aquela que assume uma função interventora em relação aos mercados e compensatória em relação à esfera social, buscando dirigir o processo evolutivo de maneira centralizada e com base em supostos interesses generalizáveis, com base na fantasiosa ideia de justiça social (Hayek, 1995, 2006; Butler, 1987; Dubiel, 1993; Harvey, 2008).

É este tipo de visão que, no meu entender, está em franco declínio, nas sociedades democráticas ocidentais, desde meados da década de 1990. Aliás, esta visão é rechaçada mesmo em países comunistas atuais, como a China, nos quais a centralização política em um Estado forte torna a evolução social algo planejado e conduzido institucionalmente, com o objetivo claro de não apenas impedir maior democratização, mas também e principalmente de evitar que capitais de alcance transnacional detonem a estabilidade daquelas economias nacionais (comunistas). Esta centralização estatal, com efeito, impediu que a China fosse afetada de maneira séria pela atual crise socioeconômica, mantendo o ritmo do crescimento econômico estável, ou seja, o controle estatal da economia nacional, de modo a contrapor-se à abertura pura e simples do mercado interno às transnacionais, impedindo a desnacionalização e a desindustrialização nativa, e foi o cerne do corrente sucesso chinês em manter ritmo estável de crescimento econômico não obstante essa crise econômica que afetou fortemente outras sociedades e, em particular, potências mundiais como os Estados Unidos, a Inglaterra e a Alemanha (Arrighi, 2008; Boltanski \& Chiapello, 2009; Napoleoni, 2014). No que tange às sociedades democráticas ocidentais, que é o que me interessa neste momento, pode-se perceber que o resultado da hegemonia neoliberal entre as décadas de 1980 e de 1990 nessas mesmas sociedades mostrou a exaustão, para não se falar da própria fragilidade, de um projeto político que centraliza a dinâmica social na ordem espontânea do mercado e que recusa um modelo ampliado de política democrática calcado em argumentos normativos e em interesses generalizáveis que se utiliza de um Estado forte, interventor e compensatório como instituição central de condução da evolução social. Hoje, os cidadãos querem segurança social realizada por meio das instituições públicas: eles afirmam tais instituições porque creem que elas podem, por meio do controle político dos poderes estruturais vigentes socialmente, da realização de direitos sociais e da oferta de oportunidades educativas e trabalhistas (para não se falar da seguridade social e dos sistemas públicos de saúde), dar-lhes um mínimo de bem-estar pessoal, assim como um mínimo de paz e de justiça sociais. Eles não estão mais dispostos a arriscar conseguir isso por meio da espontaneidade do mercado e com o abandono de uma política forte e diretiva da evolução social. Percebem que a desregulação e o enfraquecimento das instituições públicas são causa direta da crescente pauperização e desigualdade sociais. Ou seja, eles já não 
aceitam um conservadorismo político que, conforme expresso pela posição neoliberal, coloque todo o peso da integração social na espontaneidade do mercado. Os cidadãos deste novo milênio querem planejamento e centralização política, querem instituições públicas atuantes socialmente, querem um Estado forte, compensatório e interventor - eles, contrariamente à política minimalista levada a efeito pelo neoliberalismo, querem mais política.

Com efeito, este novo milênio teve início com a avaliação do fracasso teórico-prático do neoliberalismo e com a convicção, que cada dia ganha mais adeptos entre a população em geral de nossas sociedades, de que uma política planejadora precisa, por um lado, controlar e mesmo dinamizar a esfera econômico-produtiva, concomitantemente, por outro lado, ao seu trabalho integrador em termos sociais, alcançado por meio de políticas sociais calcadas na efetivação dos direitos sociais de cidadania. A receita teórico-política hegemônica, desde o início do século XXI, por conseguinte, pode ser sintetizada na seguinte programática: política forte, controle e fomento da economia nacional, realização de políticas sociais, correlatamente, no âmbito internacional, à criação de blocos político-econômicos alternativos ao horizonte euronorcêntrico (que precisará negociar com estes mesmos blocos alternativos, de modo a formar-se uma política internacional multipolar, mas concertada em objetivos mínimos, como o controle político da dinâmica econômica internacional, a realização de metas sociais e a resolução dos problemas ecológicos). E é uma receita que ganha apoio não somente entre teóricos e autoridades políticas as mais diversas, na medida em que estas últimas não podem abstrair da realização de políticas sociais como condição de legitimidade partidária e apoio administrativo por parte das camadas de eleitores; trata-se também de um apoio popular cada vez mais intenso, exatamente por atribuir, conforme dito acima, um caráter integrador e pacificador às instituições públicas de um modo geral e ao Estado de bem-estar social em particular - uma cultura democrática, assim, que aponta para o reforço e para a afirmação das instituições públicas em seu aspecto diretivo da evolução social (Danner, 2014b). Interessantemente, o sucesso de que gozam as instituições públicas, dada a consolidação dessa cultura democrática calcada na afirmação de um modelo de política e de Estado fortes, bem como contraposta ao neoliberalismo, implica em que o ideário social-democrata de conciliação entre capital e trabalho por meio do Estado de bem-estar social ganhe nova atualidade, em nossas democracias ocidentais, hodiernamente.

A nova cultura democrática contemporânea, nesse sentido, é caracterizada pela participação política direta e enfática de movimentos sociais e de iniciativas cidadãs os mais diversos frente às instituições políticas de um modo geral e em relação aos partidos políticos em particular, com a apresentação e a consolidação de agendas 
vinculadas à crítica ao capitalismo transnacionalizado e à tecnocracia política enquanto pontos imbricados da programática levada a efeito por meio da hegemonia das forças neoconservadoras contemporâneas. Portanto, essa nova cultura democrática contemporânea, caracterizada pela participação direta e incisiva de movimentos sociais e de iniciativas cidadãs, por meio de sua defesa intransigente das instituições público-políticas e da própria ação política como o cerne da constituição da sociedade e de sua transformação ao longo do tempo, representa o baluarte político-normativo mais poderoso contra a ascensão do neoconservadorismo atual. Ora, uma especificidade dessa nova cultura democrática, de nossos movimentos sociais e iniciativas cidadãs contemporâneos, pode ser percebida pela ênfase, por parte do grosso das ciências sociais contemporâneas, na consolidação de um fenômeno político-cultural importante para entender-se a política cotidiana atual, a saber, o fato de que essa nova cultura democrática caracterizada pela participação política direta por parte de movimentos sociais e de iniciativas cidadãs já não é mais conduzida ou controlada tecnocraticamente, isto é, de que ela já não depende de uma liderança política institucional ou de um partido político como a cabeça que guia esse corpo acéfalo, utilizando tal metáfora - o partido que pensaria pelos movimentos sociais, que determinaria sua senda, o tipo de atuação, seus passos. Como nos mostra Marcos Nobre (2013: 5-35) em seu texto Choque de democracia: razões da revolta, os novos movimentos de protesto e de participação políticos são marcados pela correlação entre espontaneidade política, ativismo político direto frente às instituições políticas e aos partidos políticos, e pela integração local, nacional e mesmo internacional (possibilitada, em grande medida, seja pelas alianças entre os diversos movimentos sociais e pelo entrecruzamento de suas agendas, seja pela utilização das mídias alternativas, fatores que Ihes permitem uma práxis político-cultural conjugada, concertada).

Ora, outro fator importante de tais movimentos está exatamente em sua politização, no duplo aspecto do termo: entendem sua luta como praxis política de caráter efetivo, emancipatório, participativo, que tem o direito de enquadrar o sistema político como um todo e impor - não apenas apresentar - pautas e uma agenda política às instituições públicas e aos partidos políticos; e não objetivam o fim da política, senão sua radicalização, o que significa a consolidação da participação popular junto ao sistema político, na medida em que este está submetido àquela, bem como colocam a praxis política de um modo geral e a atuação das instituições públicas em particular como o cerne da vida democrática, como a base, o instrumento para o planejamento, a orientação e a condução da evolução social, sem qualquer outro substitutivo ou alternativa à própria política (Habermas, 1991; 2005; 2009; Honneth, 2003; 2007; Giddens, 2001; Piketty, 2014). É nesse sentido que, como disse acima, essa nova cultura democrática leva a uma reconsideração da posição teóri- 
co-política social-democrata, na medida em que esta coloca a política - participação ampliada, cidadania política efetiva e instituições público-políticas fortes, interventoras e compensatórias - como o núcleo e o instrumento normativo-político-metodológico fundamentais para a autoconstituição da sociedade, para a definição dos projetos e dos rumos do desenvolvimento social como um todo.

\section{A vez de uma política forte}

No ideário social-democrata pode-se perceber, de maneira genérica, três aspectos básicos de sua posição teórico-política: (a) a afirmação da sociedade e de suas instituições enquanto estruturas objetivas que, detonando processos de socialização e de subjetivação por sobre as cabeças individuais, definem de maneira preponderante a dinâmica da evolução social, a atribuição do status quo e muito do sentido desses processos; ( $b$ ) a percepção de lutas por poder, de lutas de classe que definem o sentido e a dinâmica da estruturação das instituições, na medida em que tais lutas de classes são, em primeira mão, lutas pela definição das próprias instituições que coordenam a evolução social e os processos de socialização e de subjetivação - lutas de classe, portanto, direcionadas à orientação e à condução da evolução social; e (c) a configuração do poder econômico e político a partir dos argumentos normativos e dos interesses generalizáveis ramificados no social, o que equivale a subordinar os valores de troca do mercado capitalista aos valores de uso próprios do mundo da vida, por meio da afirmação da centralidade e do caráter diretivo da política democrática e, aqui, particularmente, do Estado de bem-estar social (Bernstein, 1982; Habermas, 1991; 2005; Hook, 1999; Kolakowski, 1999; Harrington, 1999; Flora \& Heidenheimer, 2005; Flora \& Alber, 2005). Com isso, a social-democracia dá ensejo a um modelo de política forte que deve correlata e concomitantemente garantir a viabilização do desenvolvimento econômico e de uma integração social equitativa e inclusiva, ou seja, conciliar capital e trabalho por meios políticos. Aqui reside seja o sentido das atividades estatais interventoras e fomentadoras em termos de âmbito econômico, seja a ênfase político-estatal nos direitos sociais de cidadania e nas instituições públicas de caráter socializador e de proteção social (escola, sistema público de saúde, seguridade social etc.), que têm por objetivo, no primeiro caso, impedir uma acumulação monopolística da riqueza e propiciar condições infraestruturais básicas para o desenvolvimento capitalista, bem como, no segundo caso, realizar a proteção social das classes sociais dependentes do trabalho e a garantia de sua inclusão bem-sucedida nos processos de socialização e de subjetivação (Hicks, 1999; Esping-Andersen, 2008). Trata-se, como se pode perceber, não apenas da afirmação de uma política forte e diretiva da evolução social, mas também, como condição e mesmo como consequência disso, da colocação de enormes expectativas metodológicas, programáticas e normativas às instituições políticas de um modo geral e ao 
Estado de bem-estar social em particular, na medida em que eles passam a ser o cerne para a estabilização dos problemas sociais (tensões entre capital e trabalho) e o baluarte para a condução da evolução social das e nas sociedades democráticas contemporâneas, por estas sociedades contemporâneas (Habermas, 1991; 2000; 2009; Honneth \& Hartmann, 2009; Hicks, 1999).

A crise do Estado de bem-estar social, em seu viés fiscal, político e psicossocial (O'Connor, 1977; Rosanvallon, 1981; Offe, 1984; 1989; Habermas, 2002; 2005), e o ataque neoliberal a ele desfechado mostram o quanto tais expectativas direcionadas ao campo do político apresentam contradições, e não apenas sucessos. Entretanto, o fracasso das políticas neoliberais e mesmo a consolidação de uma globalização econômica desregulada, sob o predomínio de capitais transnacionais, desde meados da década de 1990, mostram, por seu turno, o quanto a falta de uma política forte, nacional e internacionalmente, acentua os problemas da desigualdade social, da pauperização e da desestruturação das instituições públicas (Hobsbawm, 1995; Arrighi, 1998; Hardt \& Negri, 2004; Boltanski \& Chiapello, 2009). Isso as populações dos países democráticos, mormente aquelas camadas sociais com perspectivas de vida mais instáveis (que, por isso mesmo, sofrem de maneira mais aguda os problemas de desenvolvimento econômico e de mercado do trabalho - e que são mais exploradas em termos de dinâmica econômica), aprenderam a duras penas. E são essas pessoas que efetivamente consolidaram uma cultura pública calcada na afirmação e no reforço das instituições públicas em geral e do Estado de bem-estar social em particular, pondo como centro programático dessa mesma política democrática os direitos sociais de cidadania, políticas sociais e atividades interventoras que possam garantir tanto o desenvolvimento econômico, ao qual não se pode abandonar, quanto principalmente processos de socialização e de subjetivação efetivos, integrais, que não estejam determinados nem pela exploração do trabalho por parte do capital, nem pela dinâmica sempre instável do processo de acumulação capitalista da riqueza, que ainda é a base, no capitalismo contemporâneo, para a suposta realização do desenvolvimento social. Essas populações já não acreditam na retórica dos políticos e nos prognósticos dos especialistas acadêmicos sobre as reformas institucionais ou as políticas de austeridade necessárias para a afirmação do desenvolvimento econômico (leia-se: autovalorização do capital), tampouco creem que a meritocracia seja o único ou talvez o melhor critério definidor tanto do status quo como da distribuição da riqueza produzida; elas querem garantir que os direitos sociais sejam oferecidos para além de quaisquer ideologias partidárias e suas maquinações. Essas mesmas populações, portanto, percebem e afirmam a política como tendo a tarefa de garantir inclusão social efetiva para todos, protegendo suas vidas das peripécias do mercado capitalista, que é desmistificado em sua retórica de garantidor de uma integração social equitativa abrangente; o 
mercado é um lugar de exploração do trabalho com vistas à autovalorização do capital, com tendências e dinâmicas objetivas que, não controladas, submetem o trabalho a um processo de exploração e de deterioração permanente - o mundo do trabalho não é apenas o mundo da valorização tecnológica e dos altos salários das revistas de economia, senão que, de um modo geral e em perspectiva estrutural, é o âmbito da pauperização e da desigualdade sempre crescentes, dos baixos salários e da deterioração da qualidade de vida das classes trabalhadoras, da monopolização da esfera econômica por grandes grupos econômicos e da grande concentração de renda, para não se falar da consolidação de uma ordem econômica global em que os movimentos de capital e de trabalho de índole transnacional levam a um solapamento e a uma precarização cada vez maiores do trabalho assalariado e do Estado de bem-estar social (Piketty, 2014). Nesse sentido, não há mais nenhum véu dourado ou ideologia que tenham capacidade de encobrir a verdadeira face da produção material da vida no capitalismo contemporâneo: o confronto entre capital e trabalho, isto é, a autovalorização do capital por meio da exploração intensificada do trabalho é, nesse mesmo capitalismo contemporâneo, tão ou mais aguda quanto no período da acumulação originária. Sobre a realidade socioeconômica contemporânea, sobre a realidade da atual globalização econômica, diz Thomas Piketty:

\begin{abstract}
Sabemos agora que a importância global do capital neste início de século XXI não é muito diferente do que no século XVIII. Somente a forma mudou: se antes o capital era fundiário, ele tornou-se imobiliário, industrial e financeiro. Sabemos também que a concentração da riqueza permaneceu muito alta, ainda que bem menos extrema do que era há um século e nos séculos anteriores. A metade mais pobre da população continua sem posses, mas hoje existe uma classe média patrimonial que detém entre um quarto e um terço da riqueza, e os $10 \%$ mais ricos não possuem mais do que dois terços, em vez dos nove décimos de antigamente (Piketty, 2014: 368).
\end{abstract}

Portanto, as desigualdades sociais, na globalização econômica atual, mantêm-se agudas e tornam-se cada vez mais intensas, o que mostra sua condição totalmente problemática, bem como o correlato desafio político representado por essas desigualdades e pela consequente discrepância no acesso ao poder político-econômico. Isso fica evidente, em primeiro lugar, com a consolidação da globalização econômica em sua configuração atual (Chesnais, 1996; Benayon, 1998; Chossudovski, 1999; Habermas, 2003; 2006). Hoje, as grandes empresas transnacionais canalizam sua produção para países da Ásia ou da América Latina em que a mão de obra tem precária organização sindical ou consciência de classe, acostumada ao jugo do autoritarismo institucional e a uma vida de pauperização. Geralmente, pelo menos no caso da Ásia, são sociedades nas quais o poder político, centralizado na figura de um 
ditador ou de um partido burocrático, impede uma maior liberdade democrática e, com isso, consolida uma cultura cotidiana de obediência ao autoritarismo, o que facilita, no caso destas empresas, a possibilidade de se explorar mão de obra humana a bel-prazer em troca de baixíssimos salários - os mercados de trabalho da Ásia, em minha percepção, definirão muito das configurações globais do mundo do trabalho e dos mercados produtivos, não apenas porque são o destino das transnacionais, mas principalmente pelo fato de estarem instaurando em nível global um modelo político-econômico que consolida crescimento da produção, aumento da acumulação de capital e grande exploração do trabalho, definindo um tipo de globalização econômica que, não obstante ser marcada pela existência de muitos blocos de poder e centros econômicos, apresenta, como disse antes, uma mesma dinâmica, uma mesma lógica, a saber, o aumento da acumulação por meio da intensificada exploração do trabalho, que põe em perigo até mesmo as poucas conquistas trabaIhistas, em termos de Estado de bem-estar social, conquistadas pelas democracias ocidentais. Enfim, a globalização econômica consolidada tornou atual o problema da exploração do trabalho, na medida em que, naqueles continentes acima citados, aproveitou-se das condições de pobreza social, de autoritarismo institucional, de subdesenvolvimento econômico e de profunda estratificação em termos de status quo para arrefecer uma realidade de exploração do trabalho que permite uma lucratividade em contínuo e sem qualquer problematização abrangente. Pode-se pagar indefinidamente um dólar por dia a um trabalhador na China ou no Vietnã sem que essa relação de exploração desumana, literalmente de escravidão (na medida em que tal valor permite no máximo uma subsistência mínima), seja problematizada em sua crueza, nem naquele contexto, nem no horizonte das sociedades desenvolvidas (ou mesmo no Ocidente de um modo mais geral), no qual a proteção ao trabalhador e a ação dos movimentos sindicais apresentam mais efetividade e impacto político (sociedades estas que estão preocupadas, basicamente, com seu protecionismo interno, mas que sofrem, em seus sistemas de bem-estar e em seus mercados de trabalho, os efeitos do deslocamento dos mercados produtivos e de trabalho para a Ásia, percebendo, por outro lado, a ascensão de posições políticas conservadoras e o discurso ideológico calcado em políticas de austeridade como forma de resolução da atual crise socioeconômica, como se o problema estivesse no Estado de bem-estar social e nos direitos sociais de cidadania, e não na própria configuração global da economia contemporânea, determinada pelos movimentos dos capitais transnacionais).

Em segundo lugar, a crise socioeconômica hodierna, que afeta as economias nacionais ocidentais desde o início deste século, demonstra o quanto o conflito entre capital e trabalho é atual para entendermos a dinâmica da vida sociopolítica contemporânea. Essa crise, além disso, nos mostra que esse conflito, que por muito tempo 
permaneceu latente devido à programática do Estado de bem-estar social, retorna com força à agenda teórico-política e à dinâmica de nossas sociedades. Com efeito, atualmente vive-se uma queda drástica na economia produtiva e uma elevação das atividades ligadas ao capital especulativo-financeiro, bem como o deslocamento dos mercados produtivos e de trabalho para a Ásia (que passa a definir o tipo de mercado produtivo e de trabalho deste século XXI), o que ocasiona novamente endividamento galopante do Estado e falência da economia real, produtiva, ligada à industrialização - pelo menos de um modelo de industrialização endógeno e autônomo. Com isso, empresas reduzem suas atividades ou entram em processo de falência, o que ocasiona o aumento do desemprego estrutural, para não se falar também da crescente desnacionalização e desindustrialização das economias nacionais dos países subdesenvolvidos ou em desenvolvimento devido à hegemonia, neles, de capitais transnacionais, que adentram nessas mesmas economias pelo fato de não haver controles políticos adequados e uma política nacionalista consistente, mas sim abertura como que cega à globalização econômica, definida exatamente por esses capitais transnacionais do horizonte euronorcêntrico. Ora, neste caso, também pode ser percebido o fato de que as lutas em torno da definição do receituário teórico-político hegemônico em termos de resolução da referida crise colocam novamente na ordem do dia a disputa entre a programática social-democrata e a noção de políticas de austeridade própria da posição neoliberal. Neste segundo caso, há a necessidade de o Estado retirar controles políticos frente à mobilidade dos capitais, diminuindo, além disso, as políticas sociais destinadas à promoção do trabalho e à inclusão social. Ainda como parte do receituário, há de se aceitar essa dinâmica já consolidada da globalização econômica, que, com a entrada em cena das formas de trabalho próprias aos contextos subdesenvolvidos (baixos salários, jornadas laborais extenuantes, parcos direitos trabalhistas, incipiente organização sindical), apontam para a necessidade de se racionalizar o trabalho como forma de se adequar as economias nacionais e a organização político-institucional das sociedades democráticas à realidade econômico-produtiva do século XXI, em que a valorização do trabalho passa a ser determinada pela dinâmica do trabalho barato advinda da Ásia e da América Latina, dinâmica essa instaurada, aproveitada e reforçada pelas empresas transnacionais (Antunes, 2005; 2009; Gorz, 2005; Kurz, 2005). No caso da posição social-democrata, uma política forte, conforme já comentado acima, poderia, se não retomar uma forma de desenvolvimento econômico marcada por altos patamares de crescimento (isto é, de lucro), já impossível em uma realidade de globalização econômica que prioriza mão de obra da Ásia e da América Latina, e de economias desnacionalizadas e desindustrializadas, pelo menos garantir um mínimo de crescimento econômico com a proteção e a inclusão das classes trabalhadoras, a partir do reforço de um Estado forte e de uma economia nacional endógena e autônoma. 
Com isso, o crescimento das mobilizações sociais no que tange à discussão das medidas para a resolução da atual crise socioeconômica nos mostra que as populações ocidentais - e mesmo mais além - estão conscientes de que a luta entre capital e trabalho, elevada agora ao cenário internacional (e determinada por este, diga-se de passagem) por causa da globalização econômica, é atual e, se vencida pelas posições conservadoras com sua receita de políticas de austeridade, pode implicar na aceitação e na consolidação do desemprego estrutural, na desestruturação das instituições públicas e na submissão das nações (sua estrutura sociocultural e político-econômica) a uma economia globalizada que, hoje, põe em perigo o mínimo de estabilidade e de direitos sociais conquistados no Ocidente e, pior, que impede a instauração de uma forma mais justa e equilibrada de desenvolvimento econômico e social a ser perseguido em nível mundial, que possa incluir todos os continentes - na globalização econômico-cultural atual, pouco ou nada se fala da África; pouco ou nada se fala com a África -, de seu papel e de seu futuro neste século XXI. As políticas de austeridade, propugnadas pelas posições conservadoras, representam o ocaso da política democrática, a desestruturação de um modelo de política e de Estado diretivos em relação à evolução social e, assim, o solapamento das instituições públicas interventoras e compensatórias, bem como a aceitação desse tipo de globalização econômica que está calcado no modelo produtivo asiático de exploração intensificada do trabalho e crescimento da produção e da acumulação, com pouca ou nenhuma concessão de direitos e participação política democrática - modelo este sustentado pela internacionalização do capital conduzida pelas transnacionais do horizonte euronorcêntrico (Piketty, 2014; Arrighi, 1996). Acresce-se a isso o fato de a globalização econômica atual, marcada pela primazia dos capitais transnacionais do âmbito anglo-americano, levar à progressiva desnacionalização e desindustrialização das economias nacionais, mormente das nações em desenvolvimento, o que significa não apenas um processo concomitante de crise da política e do Estado, incapazes de fazer frente àqueles capitais e de garantir desenvolvimento (industrialização) econômico endógeno e autônomo e pleno emprego, mas também de desestruturação das instituições públicas em suas funções de integração social, acarretando diminuição da qualidade de vida das classes sociais menos abastadas e crescimento da desigualdade social.

Por isso, como estou defendendo, a consolidação gradual de uma cultura política pública, afirmada por estas mesmas populações, centra seu ideário na defesa e no reforço das instituições públicas, na ênfase em uma política forte, nos direitos sociais e em um Estado interventor e compensatório, fazendo da política a arena e o instrumento por excelência para a resolução dos problemas sociais e para a condução da evolução social. Trata-se de uma tendência teórico-política ao lado de outras tendências (mormente a tendência conservadora calcada na defesa de políticas de 
austeridade), mas que poderia representar uma importante alternativa para iniciativas cidadãs, movimentos sociais e partidos políticos relacionados com a tradição da esquerda teórico-política e, aqui, da política forte enquanto base para a condução da evolução social. São esses grupos que, cada vez em maior número e conscientes da atual contraposição entre capital e trabalho que dinamiza a crise socioeconômica hodierna, assumem as bandeiras da esquerda teórico-política, a saber, política e Estado fortes, controle político-estatal do capital e realização de direitos sociais de cidadania, tudo isso desde uma participação política ampliada por parte dos movimentos sociais e dos cidadãos em geral. E a esquerda teórico-política encontra nesses mesmos grupos a força política necessária para garantir sua hegemonia em nossas democracias e mais além, neste início de século XXI, contra o neoconservadorismo em defesa de políticas de austeridade. É essa esquerda teórico-política, respaldada por essa nova cultura democrática calcada na afirmação de um modelo de política e de Estado fortes, e contraposta ao neoliberalismo, que tem condições de levar a efeito uma proposta teórico-política emancipatória capaz de controlar a modernização econômico-social em curso e, de um modo mais geral, de oferecer alternativas à atual globalização econômica, que acirrou os conflitos entre capital e trabalho em escala internacional, que levou até mesmo à desnacionalização e à desindustrialização das economias nacionais subdesenvolvidas.

Ora, tal proposta teórico-política não pode esquecer uma posição social-democrata caracterizada pela conjunção entre política forte, instituições público-políticas atuantes e participação social ampliada e direta enquanto suporte político-normativo à centralidade das instituições públicas, à afirmação desse modelo de política e de Estado fortes. Em um de seus últimos textos, Habermas chama atenção exatamente para este ponto importante da social-democracia europeia, um ponto que, para ele, deve ser levado em conta quando se pensa na atual situação sociopolítica de nossas sociedades e nos desafios lançados pelo capitalismo financeiro, bem como pela hegemonia neoconservadora calcada na proposta de políticas de austeridade. De fato, a época de ouro da social-democracia europeia, marcada pela ênfase no Estado de bem-estar social, nos direitos sociais de cidadania e na cidadania política ampliada, permite, no entender de Habermas, uma comparação assaz importante entre neoliberalismo e social-democracia ao delimitar a própria posição teórico-política da esquerda frente aos desafios e às soluções próprios à modernização ocidental, a serem assumidos por essa mesma esquerda teórico-política:

Hoje em dia, o compromisso do Estado de bem-estar social, que aderiu às estruturas das sociedades, forma o fundamento em relação ao qual qualquer política tem de partir (Habermas, 2005: 150, o grifo é meu). 
Ora, ainda segundo Habermas, a diferença da social-democracia em relação ao neoliberalismo reside exatamente no fato de conferir centralidade à política democrática e às instituições público-políticas em sua correlação com a cidadania política ampliada, situação que destoa da posição neoliberal, caracterizada exatamente como sendo marcada pela autorreferencialidade e despolitização do mercado concomitantemente à tecnocracia em política. Com efeito, do êxito do projeto social-democrata de Estado de bem-estar social

nutriu-se também a concepção de uma sociedade que atua politicamente sobre si mesma mediante a vontade e a consciência dos cidadãos democraticamente unidos (Habermas, 2000: 83).

É neste contexto que a consolidação de uma nova cultura democrática, marcada pela participação política direta e incisiva por parte dos cidadãos e pela afirmação das instituições público-políticas e de um modelo de política e de Estado fortes como base da constituição e da evolução social, representa e origina uma profícua praxis política que permite o enquadramento do processo de modernização ocidental, tal como ele é levado a efeito hoje pela crescente hegemonia conservadora, politizando-o (contrariamente à despolitização desse mesmo processo por parte do neoliberalismo redivivo).

\section{Considerações finais:}

\section{uma auspiciosa perspectiva para a política democrática}

Esta tendência geral que delineei ao longo destas páginas, de uma afirmação por um número cada vez maior de pessoas da política democrática e do Estado de bem-estar social enquanto instituições centrais para o processo de evolução social, é importante para pensar-se o rumo da política democrática contemporânea e, em particular, uma perspectiva teórico-política para a esquerda, até mesmo para pensar-se uma alternativa à crise socioeconômica contemporânea, tanto na esfera das democracias quanto em termos de realidade global. Com efeito, as vozes das ruas são cada vez mais incisivas no sentido de afirmarem a política democrática como elemento basilar para a resolução dos problemas sociais, tanto em termos de controle (mas também de fomento planejado) da economia quanto no que diz respeito à realização efetiva de políticas sociais de caráter integrador e inclusivo, de forma a proteger as classes sociais dependentes do mercado de trabalho da ameaça de marginalização, de exploração e de pauperização permanentes, determinadas pela instabilidade do processo de acumulação capitalista atual, sistema capitalista que se tornou global e que elevou a instabilidade social, política e econômica para a esfera global. 
Hoje, a globalização econômica imbricou de maneira profunda dois problemas graves de nossa realidade social, a saber, a desvalorização do trabalho e a desestruturação das instituições públicas. No primeiro caso, conforme desenvolvido acima, a ênfase nos mercados de trabalho da Ásia e mesmo da América Latina, por parte dos capitais transnacionais, implica em um severo golpe às organizações trabalhistas em sua luta pela valorização do trabalho e pela domesticação social do capitalismo mundial, na medida em que aqueles capitais enfatizam exatamente um modelo econômico-político de exploração do trabalho que possui poucos freios e compensações - o modelo de trabalho hegemônico, neste início de século XXI, é o dos baixos salários, jornadas laborais extenuantes e parcos direitos trabalhistas e que nega até mesmo a força política e o poder de barganha das organizações trabalhistas. No segundo caso, a ênfase naqueles mercados de trabalho, correlatamente à mobilidade internacional dos capitais transnacionais, leva à impossibilidade de se controlar de maneira consistente, desde as instituições públicas sediadas no Estado-nação, os fluxos de capital (fundamentais para a promoção dos direitos sociais e do pleno emprego), que, ao contrário, acabam determinando os ajustes políticos desse mesmo Estado-nação, em particular a desnacionalização da economia, que leva diretamente à sua desindustrialização. Conjugado a isso, a paulatina prevalência do capital especulativo em relação ao capital produtivo também reforça a destruição da possibilidade de crescimento das economias reais, levando à progressiva desindustrialização de muitas economias nacionais por meio da ênfase na especulação e na prática rentista, contribuindo ainda mais para a consolidação do desemprego estrutural, para a desestruturação das instituições públicas e para o crescimento da marginalização e da pauperização das classes sociais dependentes do mercado de trabalho. Assim, em consequência, as instituições públicas são submetidas a um processo de desestruturação avassalador, em suas capacidades interventoras e compensatórias.

Apostarei as minhas fichas, a partir destes diagnósticos genéricos (que, de todo modo, encontram respaldo em vasta literatura nas ciências sociais - aqui citada), nos grupos sociais e nas forças políticas que, na minha compreensão, contrapõem-se às políticas de austeridade como forma de resolução da crise socioeconômica atual. Estes, conforme acredito, já vivenciaram, ao longo das décadas de 1980 e 1990, tanto a hegemonia das posições neoliberais como seus impactos sociais, políticos, culturais e econômicos em nossas sociedades, de modo que, ao perceberem o fracasso do neoliberalismo, também puderam aprender com aquela situação. São esses grupos que, hoje, defendem com unhas e dentes uma política forte, um Estado interventor e compensatório e direitos sociais de cidadania, a partir de uma contraposição às forças teórico-políticas neoconservadoras e de uma suspeição generalizada tanto ao neoliberalismo quanto ao modelo de capitalismo globalizado 
atualmente em voga. Esses grupos entendem que o conflito entre capital e trabaIho, na política e na economia, não cessa e, no caso da atual crise socioeconômica, acirrou-se, devido à globalização econômica. Por isso, para eles, não políticas de austeridade, conforme querem os conservadores, mas um modelo de política e de Estado fortes, diretivos em relação à evolução social, interventores e compensatórios, podem garantir a resolução desta crise socioeconômica com base na afirmação e na promoção do trabalho, permitindo a domesticação - ainda que sempre instável - das economias capitalistas, primeiramente em âmbito de cada nação e, depois, como passo necessário, do atual modelo de globalização econômica. A nova cultura democrática gestada pelos grupos sociais críticos do neoliberalismo, assim, reafirma e reforça as instituições políticas e a atividade política enquanto elemento diretivo da evolução social, como a forma por excelência de se orientar a esfera econômica com base em argumentos normativos e interesses generalizáveis. $\mathrm{Na}$ medida em que cresce o número de indivíduos e movimentos sociais que defendem esse modelo de política forte, interventora e compensatória, transforma-se a cultura democrática cotidiana, que passa a substituir a meritocracia e o laissez-faire, base da programática teórico-política conservadora, pela política, pelo Estado e pelos direitos sociais de cidadania como bases da evolução de nossas sociedades e mais além. Politicamente, já não se pode mais fugir destes três pontos, que se tornaram fundamentais para a estruturação das instituições políticas democráticas e, de um modo ainda mais impressionante, para a hegemonia dos partidos políticos (incluindo os partidos políticos conservadores): política forte, Estado de bem-estar social e direitos sociais de cidadania.

Ora, o crescimento de iniciativas cidadãs, de grupos culturais e de movimentos sociais contrapostos ao neoliberalismo permitiu a consolidação de uma nova cultura democrática, que é marcada exatamente, como venho dizendo, pela valorização de um modelo de Estado e de política fortes, diretivos em relação à evolução social, interventores e compensatórios, pela afirmação da política democrática, realizada no concerto entre partidos políticos e movimentos sociais, como o centro e o cerne da evolução social, pela realização universalizada dos direitos sociais de cidadania e pela colocação das instituições públicas como a base da integração social (e não mais o livre mercado nem a meritocracia pura e simplesmente). Essa nova cultura democrática permite uma resposta consistente à afirmação neoliberal da inexistência de movimentos sociais ampliados e mesmo de uma mentalidade sociocultural homogênea que pudessem sustentar macrossujeitos da evolução social com força política para, enquanto corpo coletivo, realizarem transformações abrangentes nas várias dimensões estruturais da sociedade e mesmo mais além. Hoje, esses grupos afirmadores da política, do Estado e das instituições públicas já são hegemônicos, consolidando essa nova cultura democrática que se contrapõe diretamente às posi- 
ções conservadoras em sua defesa do laissez-faire, da meritocracia e de um Estado guarda-noturno, contrapondo-se também à crescente globalização econômica dos capitais transnacionais anglo-americanos. Nossas democracias foram inundadas por estes movimentos e é por isso que assistimos a uma crescente hegemonia de partidos políticos de esquerda comprometidos com a afirmação de um modelo de política e de Estado fortes, que centralizam e orientam a evolução social. Essa esquerda, calcada nessa nova cultura democrática e apoiada nessas iniciativas cidadãs, grupos culturais e movimentos sociais, pode enfrentar com coragem e consistência as forças neoconservadoras, estabelecendo também, conforme sua orientação clássica, um projeto teórico-político de alcance internacional (na interação com forças teórico-políticas e movimentos sociais de outros países) que enfrente a descontrolada globalização econômica atual e que ofereça um projeto de futuro para nossas sociedades e para o mundo como um todo.

Ora, o neoconservadorismo atual, fundamentado na defesa de políticas de austeridade como forma de resolução da atual crise socioeconômica, precisa ser enfrentado em seu cerne teórico-político, a saber, a defesa da autorreferencialidade da esfera econômica em relação ao âmbito normativo próprio da sociedade civil e ao âmbito político próprio ao Estado e às instituições públicas. No conservadorismo, por conseguinte, a economia possui lógica imanente, interna, autorreferencial, e somente pode ser dinamizada de modo legítimo desde dentro, por suas elites econômicas e seus técnicos - a economia como monopólio dos donos do capital e dos economistas. Aqui, a economia está não apenas desligada do social, senão que também é tornada independente dele. Por isso, as políticas de austeridade atacam não a dinâmica interna da economia (já que não se pode interferir desde fora na economia, que é autorreferencial), mas sim as próprias instituições públicas e as condições de reprodução da força de trabalho. Com isso, o capitalismo perde sua vinculação social e, por outro lado, subsome a reprodução do entorno social e natural aos seus imperativos, recusando qualquer equacionamento político-institucional do próprio processo de autovalorização e de acumulação do capital, mantido ideologicamente encoberto por conta dessa defesa intransigente da autorreferencialidade econômica enquanto argumento central das políticas de austeridade, aceita até mesmo por muitas posições políticas de esquerda como o elemento básico da política econômica.

É contra essa defesa ferrenha da autorreferencialidade do sistema econômico capitalista, conforme significado pelas políticas de austeridade neoconservadoras, que as forças políticas de esquerda, em conjunção com essa nova cultura democrática afirmadora e defensora das instituições públicas, podem centrar sua atividade teórico-política. Afinal, a atual crise socioeconômica acirra no seio das sociedades ocidentais feroz luta entre capital e trabalho que Habermas, por exemplo, erronea- 
mente julgou silenciada ou mitigada pelo modelo do Estado de bem-estar social, quando, na verdade, analisando em perspectiva internacional ou mesmo para além do contexto da Europa ocidental, essa mesma luta sempre esteve evidente e intensa (na própria Europa ocidental), como o pormenoriza Thomas Piketty, ao mostrar que desde a década de 1980 a desigualdade entre capital e trabalho e a desigualdade na posse do capital cresceram vertiginosamente, de modo que o décimo por cento mais rico de cada país passou a monopolizar em torno de $65 \%$ da riqueza nacional, contra no máximo $5 \%$ da metade pobre da população, além de, no mesmo diapasão, a contribuição do trabalho para a riqueza nacional ter diminuído sensivelmente diante da concentração do capital em poucas mãos. Ora, é evidente, neste contexto, que a desigualdade de riqueza influi diretamente do tipo de estrutura sociopolítica, cultural e econômica hegemônicas, bem como no modo como elas realizam a estratificação social ao longo do tempo. O que Piketty (2014) esqueceu de dizer, em O capital no século XXI, é exatamente que a manutenção e até o acirramento da desigualdade entre capital e trabalho e na divisão do capital é consequência de lutas sociopolíticas de classe cujo resultado é representado por tais desigualdades extremas. Essa desigualdade não é um ponto de partida ou uma constatação que pode ser feita sem que se possa estudar também as lutas de classe em torno à definição das estruturas sociais - do mercado capitalista e do Estado em particular.

A conclusão de Piketty: o capital é sempre muito concentrado. E o que fazer, então? Note-se que o enfrentamento dessa questão, acirrada diante da atual crise socioeconômica, traz à tona não apenas um sensível fracasso do capitalismo enquanto sistema-mundo capaz de garantir justiça, liberdade, igualdade, democracia, promoção do meio ambiente etc., mas também a óbvia constatação de que as lutas de classe dinamizam o horizonte sociopolítico hodierno, em nossas sociedades e mais além, tendo de ser afirmadas como base do tipo hegemônico de estrutura sociopolítica, cultural e econômica que se consolida ou que deve ser consolidada como condição para a realização daqueles ideais. Certamente não é mais um atraso às teorias políticas - mormente às teorias políticas de esquerda - perceberem no reconhecimento e na afirmação das lutas de classe tanto o móbil da evolução social, da transformação das estruturas sociais ao longo do tempo, quanto o futuro do tipo hegemônico de resposta à crise socioeconômica que afeta as nossas sociedades e a realidade global deste século XXI. As lutas sociopolíticas de classe mostraram mais uma vez sua atualidade e, como o estou dizendo, são a questão-chave para pensarmos uma resposta consistente à incessante teimosia neoconservadora em resolver tal crise por meio da promoção do capital e do enquadramento do trabalho.

E essas lutas de classe contam com condições sociopolíticas e normativo-culturais muito favoráveis, hodiernamente. A mais importante delas consiste na consolidação 
dessa nova cultura democrática que é ferreamente crítica das políticas de austeridade em particular e das posições neoliberais de um modo mais geral. Essa nova cultura democrática, consolidada e afirmada por diferentes movimentos sociais, grupos culturais e iniciativas cidadãs, centra-se na defesa de um modelo de política e de Estado fortes, de instituições públicas vinculadas e atuantes socialmente, bem como de um conjunto ampliado de direitos sociais, em uma clara tomada de partido pelo trabalho em relação ao capital. Essas forças sociopolíticas estão conscientes da permanente luta entre capital e trabalho, estão conscientes das lutas de classe em torno à definição das estruturas sociopolíticas, culturais e econômicas, e não estão dispostas a abdicar desse modelo de política e de Estado fortes que centralizam e orientam o processo de evolução social. Trata-se de um novo patamar político-cultural para nossas sociedades, que permite uma consistente ação política de esquerda, e a afirmação de seu projeto teórico-político de socialismo ou de democracia radical (ainda que isso signifique, em um primeiro momento, fortalecimento das instituições públicas, afirmação de um modelo de política e de Estado diretivos em relação aos mercados e mesmo em relação à evolução social).

E esse novo patamar possibilitado pela consolidação dessa nova cultura democrática, crítica do neoliberalismo e defensora desse modelo de política e de Estado fortes, possibilita, por fim, uma contraposição aos discursos que, desde fins da década de 1980, com a crise e o esfacelamento da União Soviética, apontaram para uma crise da esquerda de um modo geral, que estaria sem um projeto teórico-político e sem sujeitos políticos ampliados que poderiam realizar transformações estruturais e abrangentes em termos de sociedade. Com efeito, esses mesmos discursos chamavam a atenção para o permanente pessimismo da esquerda, agora sem projeto teórico, sem propostas alternativas ao próprio capitalismo então hegemônico, bem como sem macrossujeitos da evolução social. Como o estou dizendo, a nova cultura democrática constitui um bloco homogêneo de movimentos sociais, de grupos culturais e de iniciativas cidadãs que defendem de maneira efetiva um modelo de política e de Estado fortes, que centralizam, que canalizam a evolução social. E esses grupos assumem o projeto da esquerda, que, de todo modo, não se confunde necessariamente com a esquerda partidária, senão que apresenta esse caráter amplo de ser dinamizado desde forças políticas as mais diversas, para além dos partidos políticos. A nova cultura democrática, enfim, na medida em que afirma a centralidade de um modelo de política e de Estado fortes como solução à crise socioeconômica atual, na medida em que é crítica do neoliberalismo, traz novamente para o centro da arena política a esquerda e seu projeto, constituindo-se em uma espécie de macrossujeito da evolução social que, se, por um lado, é multifacetado, por outro, responde como bloco político à luta de classes atual, à contraposição entre política e livre mercado, entre capital e trabalho, entre instituições públicas 
e laissez-faire. Ao responder como bloco político a esta luta, reafirma um projeto teórico-político de esquerda e torna novamente atual e intensa a luta de classes que dinamiza a crise socioeconômica hodierna, permitindo uma consistente ação política que ataca diretamente o capital em sua tendência a subsumir na dinâmica de sua autovalorização o trabalho e a reprodução social. Esta nova cultura democrática consolidou uma ideia que é central para a esquerda, o fundamento de toda sua posição teórico-política, a saber: de que tudo é política. Como diz Thomas Piketty,

[...] a democracia real e a justiça social exigem instituições específicas, que não são apenas as do mercado e que também não podem ser reduzidas às instituições parlamentares e democráticas formais (Piketty, 2014: 413).

Da mesma forma, agora segundo Habermas, a prossecução reflexiva do projeto social-democrata de Estado de bem-estar social, em sua correlação entre um modelo de política e de Estado fortes, cidadania política ampliada e direitos sociais universalizados, torna-se, para a esquerda teórico-política e para essa nova cultura democrática contemporânea de que venho falando, "[...] o único buraco de agulha por meio do qual tudo há que passar" (Habermas, 2005: 156). Eu acrescentaria aos dois posicionamentos: uma democracia efetiva e justa necessita da radicalização dessa cultura democrática politizada e atuante, que enquadra e determina configurações institucionais, projetos políticos e da atuação dos partidos políticos. Sem essa cultura democrática politizada e explosiva, a condução tecnocrática da evolução social e sua definição sistêmica e autorreferencial das instituições político-econômicas, bases da atuação conservadora, darão a tônica sem qualquer contraposição importante, mantendo hegemonia inconteste.

\begin{abstract}
I will defend the argument that since the last decade of XX century it is possible to perceive a reaffirmation of a strong, compensatory, and regulatory State, which is directive concerning social evolution. In this sense, politics turns to foreground, both in terms of affirmation of the public institutions and referring to citizen participation, as the core to the performing of transformations in all sides of the society. Against conservative tendencies in the politics, assumed again with the current social and economic crisis, and after a long time of influence of the neoliberal theory advocating for politics of austerity, we can perceive a consolidation of a democratic culture or collective mentality that affirms this directive State concerning social evolution, realizing politics of social integration and regulating economic dynamic. It is a very important reality to our democracies, because it conducts to the reinforcement of a public culture of defense of the social rights, to the affirmation of a politics that, opposed to neoliberalism, assumes the vocation of directive center of society, space of claims for justice and effective exercise of citizenship, by an always growing number of individuals, cultural groups and social movements. It is an optimistic perspective to reinforce of the political democracy that puts the State as the basic institution to the constitution of a contemporary democratic society.
\end{abstract}

Keywords: politics, State, society, economics, contemporaneity. 


\section{Referências}

ANTUNES, Ricardo. Eliminar o desemprego no capitalismo é uma ficção. Cadernos IHU em Formação, Ano 1, n. 5, 2005.

Os sentidos do trabalho: ensaio sobre a afirmação e a negação do trabalho. São Paulo: Boitempo, 2009.

ARRIGHI, Giovanni. Adam Smith em Pequim: origens e fundamentos do século XXI. São Paulo: Boitempo, 2008.

—_ A ilusão do desenvolvimento. Petrópolis: Vozes, 1998.

- . O longo século XX: dinheiro, poder e as origens de nosso tempo. Rio de Janeiro: Contraponto, 1996.

BAUMAN, Zygmunt. Capitalismo parasitário. Rio de Janeiro: Jorge Zahar Editor, 2010.

BENAYON, Adriano. Globalização versus desenvolvimento. Brasília: LGE, 1998.

BERSTEIN, Eduard. Las premisas del socialismo y las tareas de la socialdemocracia. Madrid: Siglo Veintiuno, 1982.

BOLTANSKI, Luc; CHIAPELLO, Ève. O novo espírito do capitalismo. São Paulo: Martins Fontes, 2009.

BUTLER, Eamon. A contribuição de Hayek às ideias políticas e econômicas de nosso tempo. Rio de Janeiro: Instituto Liberal, 1987.

CHESNAIS, François. A mundialização do capital. São Paulo: Xamã, 1996.

CHOSSUDOVSKY, Michel. A globalização da pobreza: impactos das reformas do FMI e do Banco Mundial. São Paulo: Moderna, 1999.

DANNER, Leno Francisco. A esquerda, o Estado, a economia: considerações em torno à crise socioeconômica contemporânea. Sociedade e Estado, v. 29, n. 2, p. 587606, 2014a.

A nova cultura democrática brasileira: ou para além da modernização conservadora. In: BAVARESCO, Agemir; SALATA, André; DANNER, Leno Francisco (Orgs.). Filosofia social \& políticas públicas, p. 266-308. Porto Alegre: Editora Fi, 2014b.

- Uma esquerda para o século XXI: para a retomada de uma política forte. Prometeus, Ano 6, n. 12, p. 101-120, 2013. 
DUBIEL, Helmut. ¿Qué es el neoconservadurismo? Barcelona: Editorial Anthropos, 1993.

DUGGAN, Lisa. The twilight of equality? Neoliberalism, cultural politics, and the attack on democracy. Boston: Beacon Press, 2003.

ESPING-ANDERSEN, Gosta. Trois leçons sur l'État-providence. Paris: Éditions du Seuil, 2008

—. Why we need a new welfare State. Oxford: Oxford University Press, 2003.

- Social foundations of postindustrial economies. Oxford: Oxford University Press, 1999.

FLORA, Peter; HEIDENHEIMER, Arnold J. The historical core and changing boundaries of the welfare State. In: FLORA, Peter; HEIDENHEIMER, Arnold J. (Eds.). The development of welfare States in Europe and América, p. 17-34. New Jersey: Transaction Publishers, 2005.

FLORA, Peter; ALBER, Jens. Modernization, democratization, and the development of welfare States in Western Europe. In: FLORA, Peter; HEIDENHEIMER, Arnold J. (Eds.). The development of welfare States in Europe and America, p. 37-80. New Jersey: Transaction Publishers, 2005.

GIDDENS, Anthony. A terceira via e seus críticos. Rio de Janeiro: Record, 2001.

GORZ, André. A crise e o êxodo da sociedade salarial. Cadernos IHU em Formação, Ano 1, n. 05, 2005.

HABERMAS, Jürgen. Ay, Europa! - Pequeños escritos políticos. Madrid: Editorial Trotta, 2009.

— O Ocidente dividido. Rio de Janeiro: Tempo Brasileiro, 2006.

_. Diagnósticos do tempo: seis ensaios. Rio de Janeiro: Tempo Brasileiro, 2005.

_. Era das transições. Rio de Janeiro: Tempo Brasileiro, 2003.

— . O discurso filosófico da modernidade: doze lições. São Paulo: Martins Fontes, 2002.

— La constelación posnacional: ensayos políticos. Barcelona: Ediciones Paidós, 2000.

La necesidad de revisión de la izquierda. Madrid: Editorial Tecnos, 1991. 
HARDT, Michael; NEGRI, Antonio. Império. Lisboa: Editora Livros do Brasil, 2004.

HARRINGTON, Michael. Socialismo: passado e futuro. In: HOOK, Sidney et alii (Orgs.). A social-democracia nos Estados Unidos, p. 87-144. Brasília: Instituto Teotônio Vilela, 1999.

HARTMANN, Martin; HONNETH, Axel. Paradojas del capitalismo. In: HONNETH, Axel. Crítica del agravio moral: patologías de la sociedad contemporánea, p. 389-422. Buenos Aires: Fondo de Cultura Económica, 2009.

HARVEY, David. O neoliberalismo: história e implicações. São Paulo: Edições Loyola, 2008.

HAYEK, Friedrich August von. The meaning of the welfare State. In: PIERSON, C.; CASTLES, F. G. (Eds.). The welfare State reader, p. 90-95. Cambridge: Polity Press, 2006.

_. Arrogância fatal: os erros do socialismo. Porto Alegre: Ortiz, 1995.

— . O caminho de servidão. Rio de Janeiro: Instituto Liberal, 1987.

- Direito, legislação e liberdade: uma nova formulação dos princípios liberais de justiça e de economia política (v. II) - A miragem da justiça social. São Paulo: Visão, 1985a.

- Direito, legislação e liberdade (v. III) - A ordem política de um povo livre. São Paulo: Visão, 1985b.

HICKS, Alexander. Social democracy and welfare capitalism: a century of income security politics. Ithaca; London: Cornell University Press, 1999.

HOBSBAWM, Eric. A Era dos Extremos: o breve século XX (1914-1991). São Paulo: Companhia das Letras, 1995.

HONNETH, Axel. Reificación: un estúdio en la teoria del reconocimiento. Buenos Aires: Katz, 2007.

- Luta por reconhecimento: a gramática moral dos conflitos sociais. São Paulo: Editora 34, 2003.

HOOK, Sidney. O sentido moral da social-democracia. In: HOOK, Sidney, et alii (Orgs.). A social-democracia nos Estados Unidos, p. 13-38. Brasília: Instituto Teotônio Vilela, 1999. 
KATZ, M. B. The undeserving poor: from the war on poverty to the war on welfare. New York: Phanteon Books, 1989.

KOLAKOWSKI, Leszek. O desafio social-democrata. In: HOOK, Sidney, et alii (Orgs.). A social-democracia nos Estados Unidos, p. 39-49. Brasília: Instituto Teotônio Vilela, 1999.

KURZ, Robert. A globalização deve se adaptar às necessidades das pessoas, e não o contrário. Cadernos IHU em Formação, Ano 1, n. 5, 2005.

NAPOLEONI, Loretta. Maonomics: por que os comunistas chineses se saem melhores capitalistas do que nós. Rio de Janeiro: Bertrand Brasil, 2014.

_ Economia bandida: a nova realidade do capitalismo. Rio de Janeiro: Difel, 2010.

NOBRE, Marcos. Choque de democracia: razões da revolta. São Paulo: Companhia das Letras, 2013.

O'CONNOR, James. USA: a crise do Estado capitalista. Rio de Janeiro: Paz e Terra, 1977.

OFFE, Claus. Capitalismo desorganizado: transformações contemporâneas do trabaIho e da política. São Paulo: Brasiliense, 1989.

. Problemas estruturais do Estado capitalista. Rio de Janeiro: Tempo Brasileiro, 1984

PIKETTY, Thomas. O capital no século XXI. Rio de Janeiro: Intrínseca, 2014.

ROSANVALLON, Pierre. La crise de l'État-providence. Paris: Éditions du Seuil, 1981.

ZURN, Michael; LEIBRIED, Stephan. Reconfiguring national constellation. In: LEIBFRIED, Stephan; ZURN, Michael (Eds.). Transformations of the State?, p. 1-36. Cambridge: Cambridge University Press, 2007. 